\title{
Enhancement of an Iraqi Radial Distribution System Performance Using Multi-Object Particle Swarm Optimization
}

\author{
Hazim S. Mohsen Alwazni", Shatha S. Abdulla Al-kubragyi \\ Electrical Engineering Dept., University of Technology-Iraq, Alsina'a street, 10066 Baghdad, Iraq. \\ *Corresponding author Email: hazimwazni83@gmail.com
}

\section{H I G H L I G H T S}

- MO-PSO algorithm for fast convergence and good-tuning feature.

- Adding DG and D-STATCOM simultaneously.

- IEEE 33-Bus and real 65-bus Iraqi RDS.

- enhancement voltage stability, improve voltage and minimize power losses by multi-objective function.

- Different cases and different load factor by using Newton Raphson load flow and MATLAB program.

\section{A R T I C L E I N F O}

Handling editor: Ivan A. Hashim

Keywords:

D-STATCOM

MOPSO algorithm

Smart distribution grid

Voltage stability

\begin{abstract}
A B S T R A C T
This paper proposes a Multi Object Particle Swarm Optimization (MOPSO) to find the optimal location and capacity of Distributed Generation and DSTATCOM device. The objective function has adapted with a multi -objectives function to improve voltage profile, the voltage stability and reduce the total power loss of the Radial Distribution System (RDS). Basically, the voltage stability index (VSI) has been used to pre-determine the optimal location of DG and D-STATCOM. Then, a MOPSO applies to achieve the suitable size of DG and D-STATCOM units with different load models. The proposed method is compared with other existing methods and it was obtained losses reductions and enhancement voltage stability and average voltage when was tested on IEEE 33bus and real Iraqi 65-bus radial distribution system through simulation using MATLAB. Furthermore, different cases were considered for using the (MOPSO) algorithm at different load factors.
\end{abstract}

\section{Introduction}

The electrical distribution system is one of the main parts of the power system has a very high $\mathrm{R} / \mathrm{X}$ ratio it causes high voltage drop and power losses which lead to voltage fluctuation, sag and instability.[1]. Different techniques have been suggested by planners for mitigating distribution systems loss and enhancement the voltage system stability issues.

Recently, small generators have been proposed that connected directly to distribution systems which are defined as Dispersed generators (DG) [2]. DG exhibits several features compared to conventional power generation such as, it can mitigate electrical losses, considers a clean technology, improves reliability, provides low-cost power and improves the power quality and the voltage profile. Furthermore, electrical system planners are applying DGs, to avoid the expansion of an existing electrical system which, become not practically feasible because of cost requirement, the complexity of protection system design, time requirements and environmental issues $[1,3,4]$.

On the other hand, shunt capacitors have been used to compensate the reactive power in distribution grids to mitigate loss and improve power factor. However, these shunt capacitors are not capable to constantly produce a variable reactive power and exhibits some operational problems like resonance [2]. So, these restrictions on the construction of shunt capacitor have persuaded the power system designers to look for some alternative solutions to increase the power system stability and efficiently transmit power over the transmission lines.

In recent times, power system planners applying Distribution Flexible AC Transmission (D-FACT) controllers, which can absorb or inject reactive power in the system as an efficient shunt capacitors substitute. [2]. The distributed static synchronous compensator (D-STATCOM) is one of the most efficient shunt D-FACTS devices due to it features like zero resonance, less harmonic distortion, low power losses, low cost, compact size and high regulatory capability $[3,5]$. 
The integration of DG and D-STATCOM has a significant role in enhancing the performance of the distribution systems. The optimal placement and the size of these devices have a great impact on the improvement of the distribution system performance such as minimizing of the distribution systems losses, enhancement the voltage stability and maintaining the voltage profile within acceptable limits [6].

The identification size and location of these devices have faced some challenges especially for large systems with a wide range of devices capacity. However, the researchers had suggested many techniques to solve the problem. The modification of the optimization techniques provides a good solution to overcoming these challenges. Generally, these optimization techniques refer to determine the optimal solution through maximizing /minimizing single or multiple objective functions [7].

Several studies have been presented under the name of met heuristic techniques such as ",Whale Optimization Algorithm(WOA)[8], Improve Differential Search Algorithm (IDEA)[9], Genetic Algorithm ( GA)[ 10],A combination of Genetic Algorithm and Particle Swarm Optimization ( GA and PSO)[11]], Particle Swarm Optimization (PSO)[12], Grey Wolf Optimization Algorithm (GWOA)[13], Harmony Search Algorithm (HSA)[14],Gravitational Search Algorithm (GSA )[15] and Slap Swarm Algorithm (SSA)[16]" to find the optimal site problem of DG and D-STATCOM in power systems. A lot of studies mentioned above have been carried out to locate the optimal location and size problems of DG and DSTATCOM devices separately or simultaneously but did not add multiple DGs and D-STATCOMs in the real systems [12, $17]$.

Remarkably, in spite of the huge methods that have been suggested by researchers to find the proper allocation to insert the DG and the D-STATCOM in a radial distribution system they did not consider a real system application. In [18] the Multi Object-Modified flower pollination algorithm MO-MFPA had been applied to insert PV and DSTATCOM simultaneously at 33, 69, and 118-bus test systems. A Latin hypercube sampling (LHS) algorithm considered to determine the location of DSTATCOM in 69 bus test system [19].

Further research on using the (VSI) and Whale Optimization (WOA) was developed to select the proper location and best size of DG to enhancing the voltage stability and increase the load ability through injecting the appropriate active and reactive powers. However, the best DG place is allocating by using the VSI to find the most sensitive buses [20]

In this paper, it is assumed that DG placement is to compensate the only real power, whereas the DSTATCOM placement is to compensate only reactive power in the distribution system

The motivation of this study is to apply a multi-object Particle Swarm Optimization Algorithm (MOPSO) for optimal placement and sizing of DG and D-STATCOM device. The algorithm based on a multi-objective PSO to minimize the system power losses and voltage profile enhancement as well as increasing voltage stability system. Verification of the proposed algorithm has been achieved on standard IEEE 33-bus and Iraqi 65-bus radial distribution systems through simulation using MATLAB. The paper is organized as follows. Section 2 explains the system modeling. Section 3 presents the problem formulation. A multi object particle swarm optimization (MO-PSO) introduces in section 4. In section 5, simulations of a distribution system under a different case with the proposed algorithm is presented. Furthermore, a performance comparison of the system is then carried out over other existing algorithms in supporting voltage stability and loss reduction in distribution networks. Finally, section 6 gives concluding remarks on the current work.

\section{System Modelling}

\subsection{D-Statcom Modelling}

D-STATCOM is a power electronic device using to control power flow[21]. D-STATCOM is one of the third generation FACTs devices that injects or absorbs the desired reactive power at the point connecting with the system [22] .According to the V-I characteristic of DSTATCOM shows in the Figure. 1 [23]. It is clear that the D-STATCOM absorb reactive power, when the reference voltage $\left(V_{R E F}\right)$ higher than the voltage of the network and the D-STATCOM inject reactive power, when the reference voltage $\left(V_{R E F}\right)$ lower than the voltage of the network.

The reactive power of D-STATCOM evaluate by

$$
\begin{aligned}
& Q_{D \text {-STATCOM }}=V_{\text {rnew }}\left(I_{D-\text { STATCOM }}\right)^{*} \\
& \text { Where } \left.I_{D-\text { STATCOM } \angle(} \angle\left(\frac{\pi}{2}\right)+\theta_{\text {new }}\right) \text { is the injected current by DSTATCOM } \\
& V_{\text {Rnew }}=V_{\text {Rnew }} \angle \theta_{\text {new }} \text { is the voltage of bus ' } \mathrm{R} \text { ' after correction. } \\
& V_{\text {Rnew }} \angle \theta_{\text {new }}=V_{S} \angle \delta-\left(R_{S R}+j X_{S R}\right) I_{L} \angle \alpha-\left(R_{S R}+j X_{S R}\right) I_{D-S T A T C O M} \angle\left(\left(\frac{\pi}{2}\right)+\theta_{\text {new }}\right)
\end{aligned}
$$

Figure.2(a) shows the single line diagram of two buses of a distribution system with D-STATCOM that is installed in bus 'R'. The Voltage of bus ' $\mathrm{R}$ ' changes from $V_{R}$ to $V_{\text {Rnew }}$ as shown in Figure.2 (b).

DSTATCOM has features like low power losses ,zero resonance, low cost, less harmonic distortion, high regulatory capability and compact size .These features made the D-STATCOM preferable to use at the distribution grids, improve the load ability, enhance the voltage profile, minimize real power loss and enhance stability[6].However, choosing the correct place of D-STATCOM is important to minimize network power loss and is subjected to the following standard limits[24].

Voltage limit: $V_{R, \min } \leq V_{R} \leq V_{R, \max }$

Injected reactive power limit: $Q_{D S T A T C o m(i)}^{\min } \leq Q_{\text {DSTATCom }(i)} \leq Q_{\text {DSTATCom }(i)}^{\max } \quad \mathrm{i}=1,2,3, \mathrm{nb}$ 
Where $V_{R, \min }$ is the minimum Voltage limits of bus ' $\mathrm{R}$ ' and $V_{R, \max }$ is the maximum Voltage limits of bus ' $\mathrm{R}$ '?

$Q_{D S T A T C O M(R)}^{\min }$ is the minimum reactive power limit of compensated bus ' $\mathrm{R}$ ' and $Q_{D S T A T C O M(R)}^{\max }$ is the maximum reactive power limit of the compensated bus ' $\mathrm{R}$ '

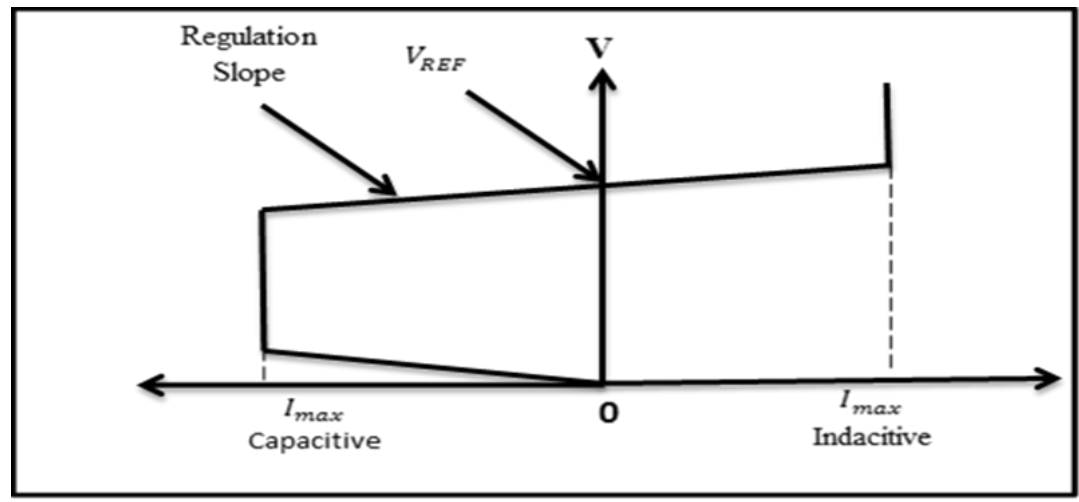

Figure 1 : V-I characteristic of DSTATCOM [23]

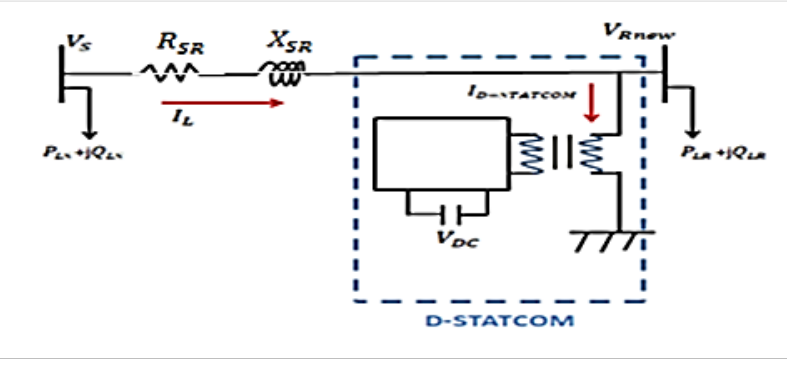

(a)

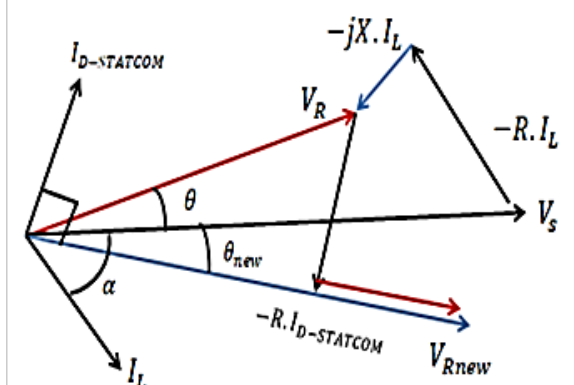

(b)

Figure 2: (a)Single line diagram of two buses with D-STATCOM[12]. (b)The phasor diagram of two buses with D-STATCOM [12]

\subsection{Distributed Generation (Dg)}

Distributed Generation (DG) is effective local power source supply power from a few watts (W) to ten megawatts (MW) which is commonly powered by renewable energy, DG exhibits several features compared to conventional power generation. It is able to inject the different value of active and reactive power and connected directly to the distribution system. [1,25].There are many types of DG which are included as renewable and non-renewable power sources such as, induction generators, micro turbines, synchronous generators, fuel cells, solar photovoltaic, wind turbines, combustion gas turbines and other small power generation sources DGs also are divided into the following four types according to the supplying power of DG[2] :

1. DG type one: DG injects real power $(\mathrm{P})$ only.

2. DG type two: DG injects both real and reactive power (P\&Q).

3. DG type three: DG injects real $(\mathrm{P})$ power but absorbs reactive power.

4. DG type four: DG injects reactive power $(\mathrm{Q})$ only.

The main features of DGs are mitigating from the greenhouse effect and using of fossil fuel, improving the voltage profile, energy security, reliability, stability and power quality as well as reduces the power losses[1]. However, the optimal locations of DGs are also important to improve the system operation characteristics and subjected to the following standard limits [9].

Voltage limit: $V_{R, \min } \leq V_{S} \leq V_{R, \max }$

$$
\text { Injected real power limits: } \quad P_{R, \min (i)} \leq P_{R(i)} \leq P_{R, \max (i)} \quad i=1,2,3, n b
$$

Where $P_{R, \min (R)}$ is the minimum real power limit of compensated bus 'R' and $P_{R, \max (R)}$ is the maximum real power limit of compensated bus ' $\mathrm{R}$ '

\section{Problem Formulation}

\subsection{Load Flow Analysis}

The power flow study is necessary for analyzing, designing and planning expansion of the power system and obtaining real and reactive power reading at each line and voltage magnitudes and their angles at each bus. Newton-Rap son method with balance condition is considered in this paper where the power-flow equation is derived in polar form and written in term of admittance matrix $\mathrm{Y}$, The relation between the bus voltages $\mathrm{V}$ and the current I injected at the network buses is described in equation(3) according to the Kirchhoff's Current Law [26] 


$$
I_{i}=\sum_{j=1}^{n} Y_{i j} V_{j}
$$

The total loss of the system evaluated by summing the losses of all the branch by Equation (4) below[3]

$$
S_{\text {total loss }}=\sum_{S=1}^{\text {no.branch }} P_{\text {loss }}(S, R)+j \sum_{S=1}^{\text {no.branch }} Q_{\text {loss }}(S, R)
$$

Where the loss in a branch between buses ' $\mathrm{S}$ 'and ' $\mathrm{R}$ ' of two buses network illustrated in figure 3 is calculate by using Equation (5) and (6) for real and reactive losses respectively.

$$
\begin{aligned}
& P_{\text {loss }}(S, R)=\left(\frac{P_{S}^{2}+Q_{S}^{2}}{\left|V_{S}\right|^{2}}\right) * R_{S R} \\
& Q_{\text {loss }}(S, R)=\left(\frac{P_{S}^{2}+Q_{S}^{2}}{\left|V_{S}\right|^{2}}\right) * X_{S R}
\end{aligned}
$$

\subsection{Objective Function}

The radial distribution networks often expose to voltage collapse due to the low level of the voltage stability index. Therefore, the voltage stability index should be considered in the objective function to avoid the voltage collapse problem occurrence. As power losses have a greater effect on utilities and represent the major concern in the power system network [3]. Hence, to avoid conflicting between the VSI and the voltage collapse, the multi objective function has been modeled in this paper. The objective function of the optimization algorithm is adapted a number of functions to be optimized simultaneously included the maximize voltage stability index, enhance the bus voltage profile and mitigate the power loss with a weighting factor. Equations (7) illustrate the objective function that is considered in this work.

$$
\text { Minimize (Fitness })=\min \left(\beta_{1}\left(\Delta P_{T L}^{D G / D S T}\right)+\beta_{2}\left(\frac{1}{A V(x)}\right)+\beta_{3}\left(\frac{1}{\Delta V S I^{D G / D S T}}\right)\right)
$$

Where $\Delta P_{T L}^{D G / D S T}$ is the ratio of total power loss after and before adding DG/D-STATCOM in RDS which given by[3]

$$
\Delta P_{T L}^{D G / D S T}=\frac{P_{T L}^{D G / D S T}}{P_{T L}}
$$

$\triangle V S I^{D G / D S T}$ is the ratio of voltage stability index of weaken bus after and before adding DG/D-STATCOM in RDS which is given by [3]

$$
\Delta V S I^{D G / D S T}=\frac{V S I_{\text {after }}^{D G / D S T}}{V I_{\text {befor }}}
$$

$A V(x)$ Is the average of buses voltages which is given by[18]

$$
A V(x)=\left(\frac{\sum_{i=1}^{n} V_{i}(x)}{n}\right)
$$

$\beta_{1}, \beta_{2}$ and $\beta_{3}$ are the weighting factors of minimization power loss and maximization AV and VSI respectively which considered (0.7), (0.3) and (0.3) respectively

\subsection{Voltage Stability Index}

It is important to consider the VSI in the objective function to avoid the voltage collapse problem. Whereas, the voltage stability was defined in[3]as "the ability of a system to maintain voltages in acceptable range so that when system nominal load is improved, the real power that delivered to the load by the system will rise and both voltage and power are controllable".

In this part, the weak buses of the system are found by applying (VSI) to mitigate the search range of the optimization algorithm. Thus, DGs and D-STATCOM will be adding in the optimal locations. Then, the multi object particle swarm optimization (MOPSO) algorithm will be utilized to determine the optimal size of both DG and D-STATCOM. The simultaneous voltage stability index value can be determined by the below relation [1]

$$
V S I_{R}=\left|V_{S}\right|^{4}-4\left(P_{R} X_{S R}-Q_{R} R_{S R}\right)^{2}-\left|V_{S}\right|^{4}\left(P_{R} R_{S R}+Q_{R} X_{S R}\right)
$$

Where $V S I_{R}$ is voltage stability index of node 'R' of two buses distribution system which was showed in Figure 3?

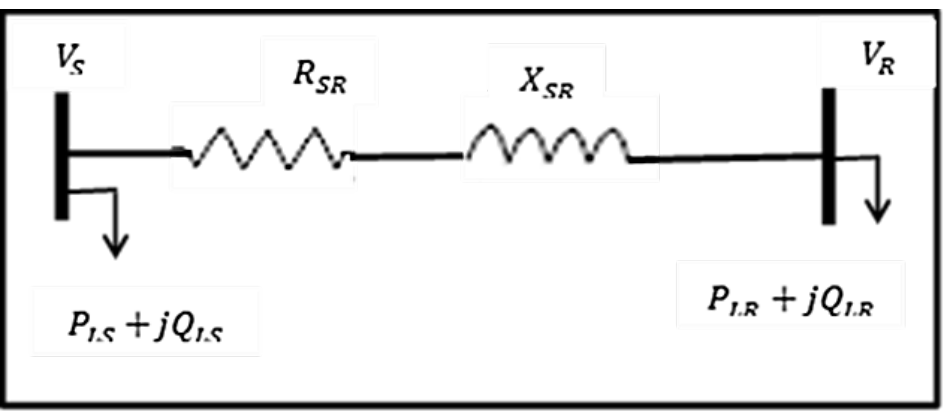

Figure 3: Single line diagram of two buses network [12] 


\section{Particle Swarm Optimization (PSO)}

A particle swarm optimization (PSO) is used in this work to determine the optimal location and size of DG/ DSTATCOM. A particle swarm optimization algorithm PSO is introduced by [27] to solve the optimization problem. The performance of the PSO algorithm is preferred due to its fast convergence feature. Figure 4 shows the flowchart of the proposed PSO. To illustrate the PSO algorithm, the steps of the algorithm are below:

Step1: adjusted the counter $\mathrm{t}=0$

$X_{i}(0)$, particles location stochastically generated where $[i=1,2,3, \mathrm{n}]$

$V_{i}(0)$ particles speed generated stochastically

$\mathrm{W}(0)$ adjusted to be 0.8 .

F (0) Run load flow program to evaluate fitness value.

Step 2: update counter $\mathrm{t}=\mathrm{t}+1$.

Step 3: update weight inertia factor according to equation 1.

Step4: update particles speed to change the particle speed according to equation 12. $V_{i}(t+1)=\mathrm{w}_{i}(t)+c_{1} t_{1}\left(\right.$ pbest $\left._{i}(\mathrm{t})-x_{i}(\mathrm{t})\right)+c_{2} t_{2}\left(\right.$ gbest $\left._{i}(\mathrm{t})-x_{i}(\mathrm{t})\right)(12)$

Where, $V_{i}(t)$ and $V_{i}(t+1)$ are previous and new speed of the current particle

$C_{1}$ And $C_{2}$ are acceleration coefficients that introduce in [28] as below:

$C_{1}=. C_{a 1}+\left(\frac{C_{b 1}-C_{a 1}}{t_{\max }}\right) * t \quad, C_{2}=. C_{a 2}+\left(\frac{C_{b 2}-C_{a 2}}{t_{\max }}\right) * t$

Where $C_{a 1}=2.5, C_{b 1}=0.5, C_{a 2}=0.5, \mathrm{c} 2 \mathrm{f}=2.5$

$r_{1}$ And $r_{2}$ are random numbers.

Step 5: update particles location according to equation 13 without violates the limits.

$x_{i}(t+1)=x_{i}(t)+V_{i}(t+1)$

Where, $x_{i}(t)$ and $x_{i}(t+1)$ are are previous and new position of Current particle

Step 6: Run load flow program to update fitness for the updated location every new iteration.

Step 7: search for the best value of fitness, if the new fitness better than the previous fitness set it as the global best fitness

Step 8: if the iteration reach the maximum iteration then stop, else return to step 2.[11]

\section{Results and Discussions}

To prove the effectiveness of the MO-PSO method, the bus voltage and losses for a standard IEEE 33-bus RDS and 65-bus Iraqi RDS have been calculated by using the Newton Rap son load flow program. Then, the proposed algorithm MO-PSO is used effectively to determine the optimal place and capacity of DG and D-STATCOM by MATLAB program. Three different cases have been considered for adding DG and D-STATCOM as presents below. The results have been compared with the results of the Bacterial Foraging Optimization Algorithm(BFOA)[29]

Case 1. System without DG and D-STATCOM.

Case 2. System with only DG.

Case 3. System with one DG and one D-STATCOM

\subsection{IEEE 33-Bus System}

An IEEE 33-bus radial distribution system is considered in this work. To demonstrate the effectiveness of the MO-PSO algorithm the total active and reactive load of the system is $3715 \mathrm{~kW}$ and $2300 \mathrm{kVar}$ respectively. The base voltage of the system is $12.66 \mathrm{kV}$ with100MVA as a base apparent power. The data of the system considered in this paper presented in[31].

The three different cases simulation results of the MO-PSO algorithm are present in Table 1. Firstly, the system simulated without DG and D-STATCOM as a base case and the result of active power losses, the minimum voltage and the minimum VSI were $210.77 \mathrm{~kW}, 0.66734 \mathrm{p} . \mathrm{u}$ and $0.90383 \mathrm{p} . \mathrm{u}$, respectively as shown in Table 1.

In case2, the total active power loss mitigated to $112.9 \mathrm{~kW}$ and the minimum VSI of the IEEE 33-bus radial distribution system improved to 0.7824 p.u. In addition, to increase the minimum voltage to 0.9422 p.u. The above enhancement comes from the impact of adding one DG (Type one PV generator) with $2460 \mathrm{~kW}$ as an optimal capacity in 26th as an optimal place that determines by the proposed method. Obviously in case adding DG as a second case has a good impact on the performance of the system and better than other method as shown in Table1. Finally, in case3, three DG and one D-STATCOM are placed in the system at optimal places to minimize the active power losses and to improve the minimum voltage and minimum VSI of this system. The evaluated results have been illustrated in Table 1. It is clear, in the third case, the total active power loss has been minimized to $62.5 \mathrm{~kW}$ and the minimum VSI and minimum voltage are improved to $0.8537 \mathrm{p} . \mathrm{u}$ and 0.9612 respectively. However, the third case better than the first two cases, the MO-PSO gives a good minimization in losses and the voltage profile of the system and the minimum VSI is improved more than the other algorithms. A comparison of the voltage profile, stability voltage index and the total power losses for the three different cases are shown in Figure 5(a), 5(b) and 5(c) respectively 


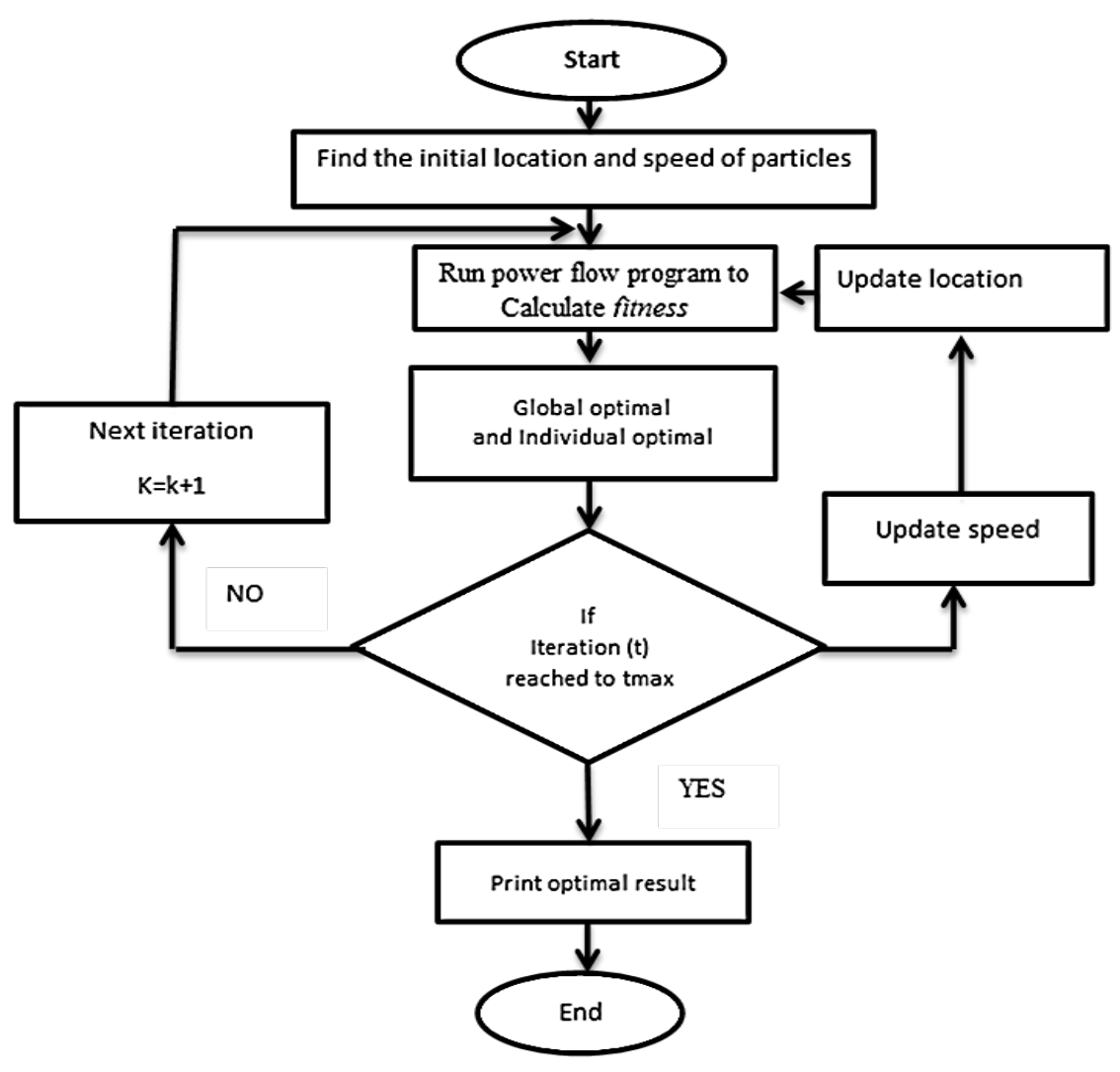

Figure 4: Flowchart of PSO Algorithm [30]

Table 1: The comparative results

\begin{tabular}{llll}
\hline & Variable & MOPSO & BFOA[29] \\
\hline Case 1 & Ploss (kW) & 210.77 & 210.98 \\
& VSImin (p.u.) & 0.66734 & 0.6610 \\
Vmin (p.u.) & 0.90383 & \\
Case 2 & Size in kw(location) & $2460(26)$ & $2200(6)$ \\
& Ploss (kW) & 112.90 & 113.14 \\
& VSImin (p.u.) & 0.7824 & 0.7640 \\
Case 3 & Vmin (p.u.) & 0.9422 & 0.9368 \\
& Size in kvar (location) & $1180(30)$ & $1094.6(30)$ \\
& Size in kW (location) & $2880(7)$ & $1239.8(10)$ \\
& Ploss (kW) & 62.5 & 70.87 \\
& VSImin (p.u.) & 0.8537 & 0.8465 \\
& Vmin (p.u.) & 0.9612 & 0.9615 \\
\hline
\end{tabular}

\subsection{Numerical Results of Iraqi 65-Bus System}

The radial distribution system is shown in Figure (6) is an Iraqi real 65-bus RDS considered in this paper as a second test system. The system is one feeder of Sadat Al-Hindiya district secondary power station which supply the Al-Zahraa neighborhood, one of the neighborhoods of Sadat Al-Hindiya district is located south of Al-Musayyib city in Babil Governorate, Iraq.

The system data present in Table 2 is identified after determining the length of line and location of buses by Geographic Position System (GPS) and plot the real system by Geographic Information System (GIS) [32] as shown in Figure (7) incorporate with the Iraqi ministry of electricity. The Iraqi system tested under three different cases and three different load factors with base voltage and base apparent power are $11 \mathrm{kV}$ and $100 \mathrm{MVA}$ respectively. The total active and reactive load of this RDS is $5669.1 \mathrm{~kW}$ and $3560.6 \mathrm{kVar}$ respectively. In the first case before adding DG and DSTATCOM the active power losses, the minimum voltage and the minimum VSI were $446.2 \mathrm{~kW}, 0.8962 \mathrm{p} . \mathrm{u}$ and $0.645 \mathrm{p} . \mathrm{u}$ respectively for 1 load factor as illustrated in Table 3.In case2, the total active power loss mitigated to $125.9 \mathrm{~kW}$ and the minimum VSI of Iraqi 65 -bus radial distribution system is improved to $0.8333 \mathrm{p}$.u .In addition, to increase the minimum voltage to $0.9555 \mathrm{p} . \mathrm{u}$.The above enhancement comes from the impact of adding one DG (Type one) with $4940 \mathrm{~kW}$ as an optimal capacity in 51 th bus as an 
optimal place that determine by the proposed method for 1 load factor. Obviously in the case of adding DG as a second case gives a good impact on the performance of the system as shown in Table 3.

In case3, both one D-STATCOM and three DG are installed at the optimal bus to minimize the power losses and to enhance the minimum VSI of the system. The obtained results are presented in Table 3.

The evaluated results have been illustrated in Table 3. It is clear, in the third case, the total active power loss has been minimized to $26.3 \mathrm{~kW}$ and the minimum VSI and minimum voltage are improved to $0.9503 \mathrm{p} . \mathrm{u}$ and 0.9873 respectively. However, the third case better than the first two cases, the MO-PSO gives a good minimization in losses and an improvement in voltage profiles of the system and in the minimum VSI in all three cases.

Remarkably, it is able noticed that as load factor increases the total losses increase for each three cases but the minimum voltage and VSI reduce at the same time. A comparison of the voltage profile, stability voltage index and the total power losses for the three different cases are shown in Figure 8(a), 8(b) and 8(c) respectively.

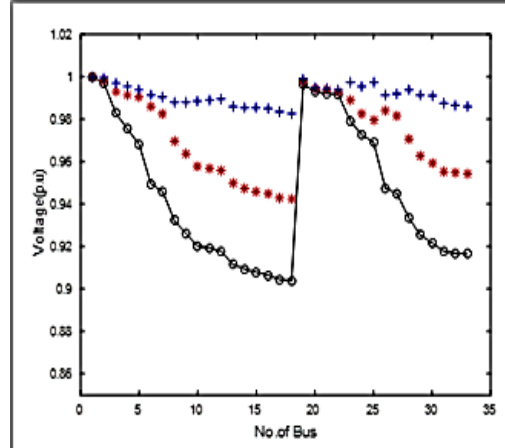

(a)

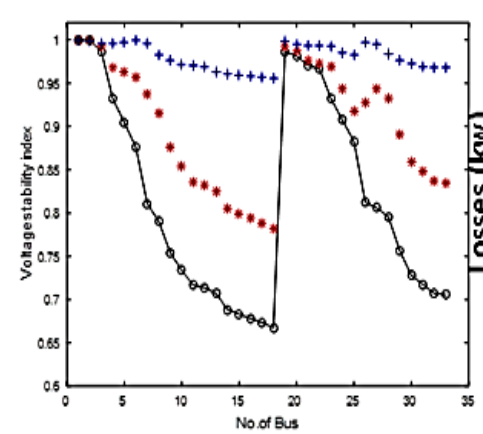

(b)

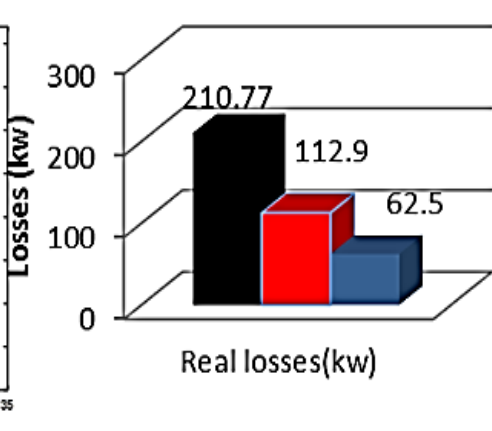

(c)

without DG\&DSTATCOM

with1 DG

with 1 DG\& 1 DSTATCOM

Figure 5: (a) voltage profiles comparison of 33-bus system for different cases (b) VSI comparison of 33-bus system for different cases and (c) power losses comparison of 33-bus system for different cases.

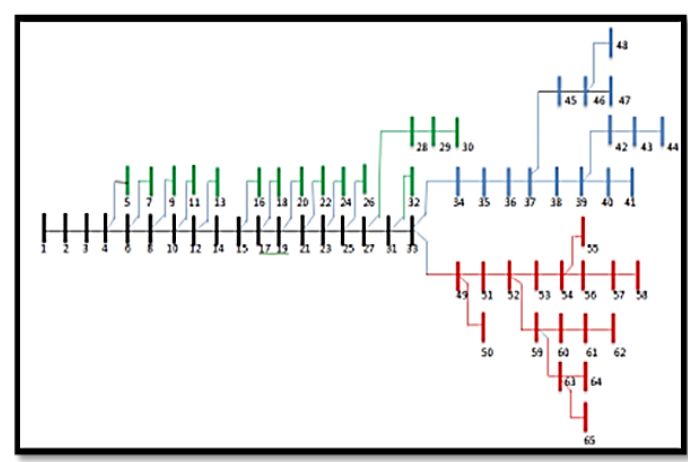

Figure 6: Iraqi real 65-bus configuration

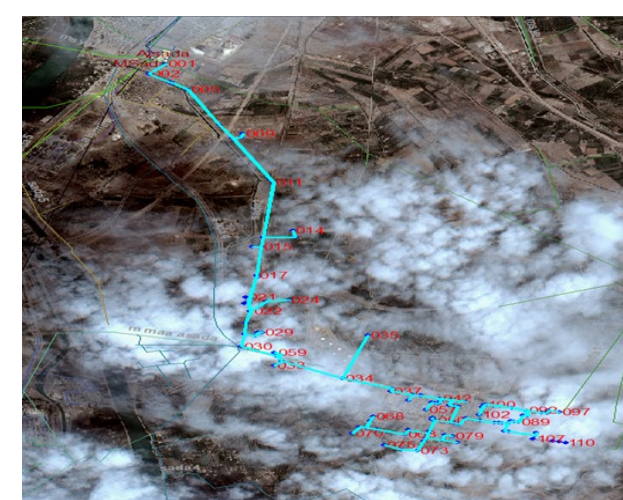

Figure 7: Data of Iraqi 65 bus system

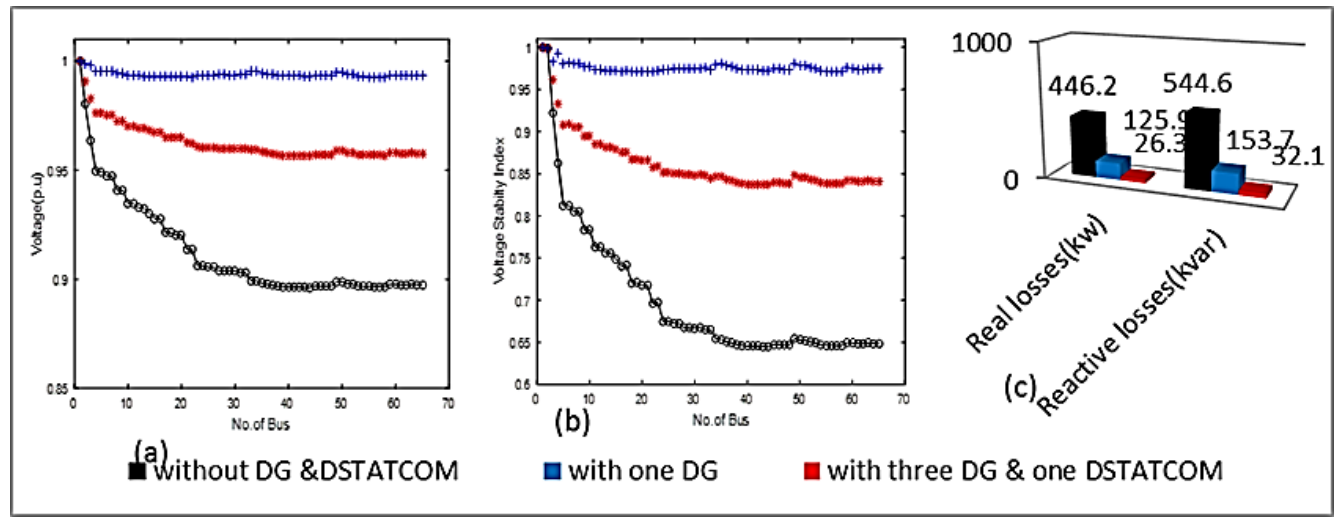

Figure 8: (a) Comparison of voltage profiles for different cases in Iraqi 65-bus system, (b) Comparison of VSI for different cases in Iraqi 65-bus system and (c) Comparison of line losses for different cases in Iraqi 65-bus system 
Table 2: Data of Iraqi 65 bus system

\begin{tabular}{|c|c|c|c|c|c|c|c|c|c|c|c|c|c|}
\hline & $\begin{array}{l}T \\
\stackrel{0}{8} \\
\end{array}$ & $\begin{array}{l}\mathrm{T} \\
\mathrm{o}\end{array}$ & R(p.u) & X (p.u) & $\begin{array}{c}\boldsymbol{P}_{\boldsymbol{L}} \\
(\mathrm{MW})\end{array}$ & $\begin{array}{c}\boldsymbol{Q}_{\boldsymbol{L}} \\
\text { (MVA } \\
\text { R) }\end{array}$ & & $\begin{array}{l}\overline{0} \\
\stackrel{0}{8}\end{array}$ & $\begin{array}{l}\mathrm{T} \\
\mathrm{o}\end{array}$ & $\begin{array}{c}\mathrm{R} \\
\text { (p.u) }\end{array}$ & $\begin{array}{c}\text { X } \\
\text { (p.u) }\end{array}$ & $\begin{array}{l}\boldsymbol{P}_{\boldsymbol{L}} \\
(\mathrm{M} \\
\mathrm{W})\end{array}$ & $\begin{array}{c}\boldsymbol{Q}_{\boldsymbol{L}} \\
(\mathrm{MVA} \\
\mathrm{R})\end{array}$ \\
\hline 1 & 1 & 2 & 0.2163 & 0.264099 & 0.1063 & 0.0659 & 3 & 3 & 3 & 0.0061 & 0.0075 & 0.17 & 0.1054 \\
\hline & & & 63 & & & & 3 & 2 & 4 & 75 & 38 & 00 & \\
\hline 2 & 2 & 3 & 0.1847 & 0.225542 & 0.1063 & 0.0659 & $\begin{array}{l}3 \\
4\end{array}$ & 3 & $\begin{array}{l}3 \\
5\end{array}$ & $\begin{array}{l}0.0451 \\
25\end{array}$ & $\begin{array}{l}0.0550 \\
81\end{array}$ & 0.10 & 0.0659 \\
\hline 3 & 3 & 4 & $\begin{array}{l}0.1593 \\
63\end{array}$ & 0.194523 & 0.0 & 0.000 & $\begin{array}{l}3 \\
5\end{array}$ & $\begin{array}{l}3 \\
4\end{array}$ & $\begin{array}{l}3 \\
6\end{array}$ & $\begin{array}{l}0.0320 \\
63\end{array}$ & $\begin{array}{l}0.0391 \\
37\end{array}$ & $\begin{array}{l}0.10 \\
63\end{array}$ & 0.0659 \\
\hline 4 & 4 & 5 & $\begin{array}{l}0.0631 \\
8\end{array}$ & 0.077113 & 0.1700 & 0.1054 & $\begin{array}{l}3 \\
6\end{array}$ & $\begin{array}{l}3 \\
5\end{array}$ & $\begin{array}{l}3 \\
7\end{array}$ & $\begin{array}{l}0.0308 \\
75\end{array}$ & $\begin{array}{l}0.0376 \\
87\end{array}$ & 0.0 & 0.000 \\
\hline 5 & 4 & 6 & $\begin{array}{l}0.0256 \\
50\end{array}$ & 0.031309 & 0 & 0 & $\begin{array}{l}3 \\
7\end{array}$ & $\begin{array}{l}3 \\
6\end{array}$ & $\begin{array}{l}3 \\
8\end{array}$ & $\begin{array}{l}0.0465 \\
50\end{array}$ & $\begin{array}{l}0.0568 \\
20\end{array}$ & $\begin{array}{l}0.10 \\
63\end{array}$ & 0.0659 \\
\hline 6 & 6 & 7 & $\begin{array}{l}0.0114 \\
00\end{array}$ & 0.013915 & 0.1063 & 0.0659 & $\begin{array}{l}3 \\
8\end{array}$ & $\begin{array}{l}3 \\
7\end{array}$ & $\begin{array}{l}3 \\
9\end{array}$ & $\begin{array}{l}0.0152 \\
00\end{array}$ & $\begin{array}{l}0.0185 \\
54\end{array}$ & 0.0 & 0.0 \\
\hline 7 & 6 & 8 & $\begin{array}{l}0.0776 \\
63\end{array}$ & 0.094797 & 0.0 & 0.00 & $\begin{array}{l}3 \\
9\end{array}$ & $\begin{array}{l}3 \\
8\end{array}$ & $\begin{array}{l}4 \\
0\end{array}$ & $\begin{array}{l}0.0567 \\
63\end{array}$ & $\begin{array}{l}0.0692 \\
86\end{array}$ & $\begin{array}{l}0.17 \\
00\end{array}$ & 0.1054 \\
\hline 8 & 8 & 9 & $\begin{array}{l}0.0047 \\
50\end{array}$ & 0.005798 & 0.1063 & 0.0659 & $\begin{array}{l}4 \\
0\end{array}$ & $\begin{array}{l}3 \\
9\end{array}$ & $\begin{array}{l}4 \\
1\end{array}$ & $\begin{array}{l}0.0187 \\
63\end{array}$ & $\begin{array}{l}0.0229 \\
02\end{array}$ & 0.0 & 0.0 \\
\hline 9 & 8 & $\begin{array}{l}1 \\
0\end{array}$ & $\begin{array}{l}0.0736 \\
25\end{array}$ & 0.089869 & 0.0 & 0.000 & $\begin{array}{l}4 \\
1\end{array}$ & $\begin{array}{l}4 \\
0\end{array}$ & $\begin{array}{l}4 \\
2\end{array}$ & $\begin{array}{l}0.0211 \\
38\end{array}$ & $\begin{array}{l}0.0258 \\
01\end{array}$ & $\begin{array}{l}0.10 \\
63\end{array}$ & 0.0659 \\
\hline $\begin{array}{l}1 \\
0\end{array}$ & $\begin{array}{l}1 \\
0\end{array}$ & $\begin{array}{l}1 \\
1\end{array}$ & $\begin{array}{l}0.0223 \\
25\end{array}$ & 0.027251 & 0.1063 & 0.0659 & $\begin{array}{l}4 \\
2\end{array}$ & $\begin{array}{l}3 \\
9\end{array}$ & $\begin{array}{l}4 \\
3\end{array}$ & $\begin{array}{l}0.0456 \\
00\end{array}$ & $\begin{array}{l}0.0556 \\
61\end{array}$ & $\begin{array}{l}0.17 \\
00\end{array}$ & 0.1054 \\
\hline 1 & 1 & 1 & 0.0249 & 0.03044 & 0.0 & 0.000 & 4 & 4 & 4 & 0.0220 & 0.0269 & 0.10 & 0.0659 \\
\hline 1 & 0 & 2 & 38 & & & & 3 & 2 & 4 & 88 & 61 & 63 & \\
\hline 1 & 1 & 1 & 0.0660 & 0.080592 & 0.1700 & 0.1054 & 4 & 4 & 4 & 0.0263 & 0.0321 & 0.17 & 0.1054 \\
\hline 2 & 2 & 3 & 25 & & & & 4 & 3 & 5 & 63 & 79 & 00 & \\
\hline 1 & 1 & 1 & 0.0323 & 0.039426 & 0.1700 & 0.1054 & 4 & 3 & 4 & 0.0375 & 0.0458 & 0.0 & 0.00 \\
\hline 3 & 2 & 4 & 00 & & & & 5 & 7 & 6 & 25 & 04 & & \\
\hline 1 & 1 & 1 & 0.0308 & 0.037687 & 0.0 & 0.0 & 4 & 4 & 4 & 0.0558 & 0.0681 & 0.10 & 0.0659 \\
\hline 4 & 4 & 5 & 75 & & & & 6 & 5 & 7 & 13 & 27 & 63 & \\
\hline 1 & 1 & 1 & 0.0315 & 0.038557 & 0.1700 & 0.1054 & 4 & 4 & 4 & 0.0076 & 0.0092 & 0.10 & 0.0659 \\
\hline 5 & 5 & 6 & 88 & & & & 7 & 6 & 8 & 00 & 77 & 63 & \\
\hline 1 & 1 & 1 & 0.0895 & 0.109292 & 0.0 & 0.0 & 4 & 4 & 4 & 0.0213 & 0.0260 & 0.0 & 0.000 \\
\hline 6 & 5 & 7 & 38 & & & & 8 & 6 & 9 & 75 & 91 & & \\
\hline 1 & 1 & 1 & 0.0171 & 0.020873 & 0.1063 & 0.0659 & 4 & 3 & 5 & 0.0099 & 0.0121 & 0.10 & 0.0659 \\
\hline 7 & 7 & 8 & 00 & & & & 9 & 3 & 0 & 75 & 76 & 63 & \\
\hline 1 & 1 & 1 & 0.0147 & 0.017974 & 0.0 & 0.000 & 5 & 4 & 5 & 0.0296 & 0.0362 & 0.17 & 0.1054 \\
\hline 8 & 7 & 9 & 25 & & & & 0 & 9 & 1 & 88 & 38 & 00 & \\
\hline 1 & 1 & 2 & 0.0156 & 0.019133 & 0.1063 & 0.0659 & 5 & 4 & 5 & 0.0064 & 0.0078 & 0.0 & 0.000 \\
\hline 9 & 9 & 0 & 75 & & & & 1 & 9 & 2 & 13 & 27 & & \\
\hline 2 & 1 & 2 & 0.0952 & 0.11625 & 0.0 & 0.0 & 5 & 5 & 5 & 0.0812 & 0.0991 & 0.17 & 0.1054 \\
\hline $\mathbf{0}$ & 9 & 1 & 38 & & & & 2 & 1 & 3 & 25 & 46 & 00 & \\
\hline 2 & 2 & 2 & 0.1218 & 0.148718 & 0.1700 & 0.1054 & 5 & 5 & 5 & 0.0161 & 0.0197 & 0.0 & 0.000 \\
\hline 1 & 1 & 2 & 38 & & & & 3 & 2 & 4 & 50 & 13 & & \\
\hline 2 & 2 & 2 & 0.1130 & 0.137992 & 0.0 & 0.0 & 5 & 5 & 5 & 0.0185 & 0.0226 & 0.17 & 0.1054 \\
\hline 2 & 1 & 3 & 50 & & & & 4 & 3 & 5 & 25 & 12 & 00 & \\
\hline 2 & 2 & 2 & 0.0163 & 0.020003 & 0.1700 & 0.1054 & 5 & 5 & 5 & 0.0187 & 0.0229 & 0.17 & 0.1054 \\
\hline 3 & 3 & 4 & 88 & & & & 5 & 4 & 6 & 63 & 02 & 00 & \\
\hline 2 & 2 & 2 & 0.0114 & 0.013915 & 0.0 & 0.0 & 5 & 5 & 5 & 0.0028 & 0.0034 & 0.10 & 0.0659 \\
\hline 4 & 3 & 5 & 00 & & & & 6 & 4 & 7 & 50 & 79 & 63 & \\
\hline 2 & 2 & 2 & 0.0016 & 0.002029 & 0.1063 & 0.0659 & 5 & 5 & 5 & 0.0135 & 0.0165 & 0.10 & 0.0659 \\
\hline 5 & 5 & 6 & 63 & & & & 7 & 6 & 8 & 38 & 24 & 63 & \\
\hline 2 & 2 & 2 & 0.0275 & 0.033628 & 0.0 & 0.0 & 5 & 5 & 5 & 0.0125 & 0.0153 & 0.0 & 0.00 \\
\hline 6 & 5 & 7 & 50 & & & & 8 & 7 & 9 & 88 & 65 & & \\
\hline 2 & 2 & 2 & 0.0085 & 0.010436 & 0.1063 & 0.0659 & 5 & 5 & 6 & 0.0095 & 0.0115 & 0.10 & 0.0659 \\
\hline 7 & 7 & 8 & 50 & & & & 9 & 2 & 0 & 00 & 96 & 63 & \\
\hline 2 & 2 & 2 & 0.0116 & 0.014205 & 0.1700 & 0.1054 & 6 & 5 & 6 & 0.0501 & 0.0611 & 0.17 & 0.1054 \\
\hline 8 & 8 & 9 & 38 & & & & 0 & 9 & 1 & 13 & 69 & 00 & \\
\hline 2 & 2 & 3 & 0.0209 & 0.025511 & 0.1700 & 0.1054 & 6 & 6 & 6 & 0.0261 & 0.0318 & 0.10 & 0.0659 \\
\hline 9 & 9 & 0 & 00 & & & & 1 & 1 & 2 & 25 & 89 & 63 & \\
\hline 3 & 2 & 3 & 0.0156 & 0.019133 & 0.0 & 0.0 & 6 & 5 & 6 & 0.0228 & 0.0278 & 0.0 & 0.000 \\
\hline $\mathbf{0}$ & 7 & 1 & 75 & & & & 2 & 9 & 3 & 00 & 30 & & \\
\hline 3 & 3 & 3 & 0.0216 & 0.026381 & 0.1700 & 0.1054 & 6 & 6 & 6 & 0.0211 & 0.0258 & 0.17 & 0.1054 \\
\hline 1 & 1 & 2 & 13 & & & & 3 & 3 & 4 & 38 & 01 & 00 & \\
\hline 3 & 3 & 3 & 0.0691 & 0.084361 & 0.0 & 0.0 & 6 & 6 & 6 & 0.0249 & 0.0304 & 0.17 & 0.1054 \\
\hline 2 & 1 & 3 & 13 & & & & 4 & 3 & 5 & 38 & 39 & 00 & \\
\hline
\end{tabular}


Table 3: Numerical results of Iraqi 65-bus system

\begin{tabular}{|c|c|c|c|c|c|c|c|c|c|}
\hline & & Case1 & & & Case2 & & & Case3 & \\
\hline Load factor & 0.7 & 1 & 1.2 & 0.7 & 1 & 1.2 & 0.7 & 1 & 1.2 \\
\hline $\begin{array}{l}\text { Size in kVAr } \\
\text { (location) }\end{array}$ & & & & & & & $1950(53)$ & $2830(38)$ & $2770(29)$ \\
\hline $\begin{array}{l}\text { Size in kW } \\
\text { (location) }\end{array}$ & & & & $\begin{array}{l}3450 \\
(59)\end{array}$ & $\begin{array}{l}4940 \\
(51)\end{array}$ & $\begin{array}{l}5520 \\
(59)\end{array}$ & $\begin{array}{l}900(11) \\
290(12) \\
2050(52)\end{array}$ & $\begin{array}{l}20(48) \\
1390(30) \\
3000(38)\end{array}$ & $\begin{array}{l}610(2) \\
3110(29) \\
2510(46)\end{array}$ \\
\hline Ploss (kW) & 204.8 & 446.2 & 673.5 & 61.1 & 125.9 & 190.3 & 12.4 & 26.3 & 35.2 \\
\hline Qloss(kvar) & 250 & 544.6 & 822 & 74.6 & 153.7 & 232.2 & 15.2 & 32.1 & 43 \\
\hline VSImin (p.u.) & 0.7474 & 0.645 & 0.578 & 0.882 & 0.833 & 0.784 & 0.9519 & 0.9503 & 0.9141 \\
\hline Vmin (p.u.) & 0.9298 & 0.8962 & 0.872 & 0.969 & 0.955 & 0.941 & 0.9878 & 0.9873 & 0.9778 \\
\hline
\end{tabular}

\section{CONCLUSION}

In this paper, a multi object particle swarm algorithms (MO-PSO) has been proposed to enhance the system stability of smart Distribution Grids. The MO-PSO is employed to solve a multi-objective function including enhancement the average voltage and voltage stability and minimizing the total power loss by finding the optimal locations and sizes of DG and DSTATCOM in the power distribution system. Actually, simulation results demonstrated that the MO-PSO algorithm improves the average voltage and voltage stability and minimizing the total power loss of distribution networks when compared with other optimization algorithms under a different cases . Generally, it can be concluded that the MO-PSO can be simply used as an intelligent real -time tool with any large distribution system.

\section{Nomenclatures}

\begin{tabular}{|c|c|}
\hline$A V(x)$ & Average of buses voltage \\
\hline$c_{2}, c_{1}$ & Acceleration coefficient \\
\hline gbest $^{t-1}$ & Global best location \\
\hline$I_{D-S T A T C O M}$ & Injected current of D-STATCOM \\
\hline$I_{L}$ & Current pass between two buses \\
\hline$n$ & Total number of buses in the network \\
\hline pbest $_{i}$ & Particl best location \\
\hline$P_{R(R)}$ & Real power of DG at bus ' $R$ ' \\
\hline$P_{T L}$ & Total Loss before insert device \\
\hline$P_{R, \min (R)}:$ & Minimum active power \\
\hline$P_{R, \max (R)}$ & Maximum active power \\
\hline$P_{\text {loss }}(S, R)$ & Active losses of branch between buses R and S \\
\hline$Q_{\text {loss }}(S, R)$ & Reactive losses of branch betweenBus $\mathrm{R}$ and $\mathrm{S}$ \\
\hline$Q_{D S T A T C O M}^{\min }(R)$ & Minimum limit of compensated Power \\
\hline$Q_{D S T A T C O M}^{\max }(R)$ & $\begin{array}{l}\text { Maximum limit of compensated } \\
\text { Power }\end{array}$ \\
\hline$R_{S R}+j X_{S R}$ & Impedance of branch between buses $\mathrm{R}$ and $\mathrm{S}$ \\
\hline$S_{\text {total loss }} \mathrm{T}$ & Total power losses \\
\hline $\mathrm{t}$ & Number of iterations \\
\hline$V_{R}$ & Voltage at receiving end bus \\
\hline$V_{S}$ & Voltage at receiving end bus \\
\hline$V_{\text {Rnew }}$ & $\begin{array}{l}\text { Voltage at receiving end bus after } \\
\text { Compensated }\end{array}$ \\
\hline$V_{R, \min }$ & Minimum Voltage limits of bus $\mathrm{R}$ \\
\hline$V_{R, \max }$ & $\begin{array}{l}\text { Maximum } V_{R, \max } \text { Voltage limits of } \\
\text { Bus R }\end{array}$ \\
\hline$V S I_{R}$ & Voltage stability index of node ' $R$ ' \\
\hline$V_{i}(t)$ & Velocities of the particles \\
\hline$v_{i}(t+1)$ & Updated velocities of the particles \\
\hline
\end{tabular}




$\begin{array}{ll}\mathrm{W} & \text { weight inertia } \\ x_{i}(t) & \text { Position of the particles } \\ x_{i}(t+1) & \text { Updated position of the particles } \\ \theta_{\text {new }} & \text { Phase angle between } V_{R \text { Rew }} \text { and } V_{S} \\ \delta & \text { Phase angle of sending end voltage } \\ \alpha & \text { Phase angle of Current pass between } \\ \beta_{1}, \beta_{2} \text { and } \beta_{3} & \text { Two buses } \\ \end{array}$

Author contribution

All authors contributed equally to this work.

Funding

This research received no specific grant from any funding agency in the public, commercial, or not-for-profit sectors.

Data availability statement

The data that support the findings of this study are available on request from the corresponding author.

Conflicts of interest

The authors declare that there is no conflict of interest.

\section{References}

[1] S. R. Salkuti, Optimal location and sizing of DG and D-STATCOM in distribution networks, Indones. J. Electr. Eng. Comput. Sci., 16 (2019) 1107-1114. http://doi.org/10.11591/ijeecs.v16.i3.pp1107-1114

[2] T. Yuvaraj and K. Ravi, Multi-objective simultaneous DG and DSTATCOM allocation in radial distribution networks using cuckoo searching algorithm, Alexandria Eng. J., 57. (2018). http://doi.org/10.1016/j.aej.2018.01.001

[3] Y. Thangaraj and R. Kuppan, Multi-objective simultaneous placement of DG and DSTATCOM using novel lightning search algorithm, J. Appl. Res. Technol., 15 (2017) 477-491. http://doi.org/10.1016/i.jart.2017.05.008

[4] Rashid H. Al-Rubayi and Shaimaa Sh. Abd Alhalim, Stability Improvement Of the (400kV) Iraqi Grid using the best FACTS Devices, Eng.Tech. J., 33 (2015) 1598-1618. http://dx.doi.org/10.30684/etj.33.7A.5

[5] A. R. Gupta and A. Kumar, Energy Savings Using D-STATCOM Placement in Radial Distribution System, Procedia Comput. Sci., 70 (2015) 558-564. http://doi.org/10.1016/j.procs.2015.10.100

[6] O. P. Mahela and A. G. Shaik, A review of distribution static compensator, Renew. Sustain. Energy Rev., 50 (2015) 531546. http://doi.org/10.1016/j.rser.2015.05.018

[7] Mohammad Kiani-Moghaddam ,Mojtaba Shivaie ,Philip D. WeinsierP. Systems, Modern Music- Inspired Optimization Algorithms for Electric Power Systems Springer Nature Switzerland AG 2019 .

[8] T. Yuvaraj, K. R. Devabalaji, and S. B. Thanikanti, Simultaneous Allocation of DG and DSTATCOM Using Whale Optimization Algorithm, Iran. J. Sci. Technol. - Trans. Electr. Eng., 44 (2020) 879-896. https://doi.org/10.1007/S40998019-00272-W

[9] S. K. Injeti, A Pareto optimal approach for allocation of distributed generators in radial distribution systems using improved differential search algorithm, J. Electr. Syst. Inf. Technol., 5 (2018) 908-927. https://doi.org/10.1016/j.jesit.2016.12.006

[10] I. I. Ali and O. Y. Saeed, Optimal Reconfiguration and Distributed Generation placement in Baghdad Distribution Sector, Eng. Technol. J., 36 (2018) 333-343. https://doi.org/10.30684/etj.36.3a.13

[11] M. H. Moradi and M. Abedini, A combination of genetic algorithm and particle swarm optimization for optimal DG location and sizing in distribution systems, Int. J. Electr. Power Energy Syst., 34 (2012) 66-74. https://doi.org/ 10.1016/j.ijepes.2011.08.023

[12] S. Devi and M. Geethanjali, Optimal location and sizing determination of Distributed Generation and DSTATCOM using Particle Swarm Optimization algorithm, Int. J. Electr. Power Energy Syst., 62 (2014) 562-570 https://doi.org/10.1016/j.ijepes.2014.05.015

[13] S. F. Mekhamer, R. H. Shehata, A. Y. Abdelaziz, and M. A. Al-Gabalawy, Enhancing radial distribution system performance by optimal placement of DSTATCOM, Int. J. Electr. Comput. Eng., 10 (2020) $2850-2860$. https://doi.org/10.11591/ijece.v10i3. 2850-2860

[14] T. Yuvaraj, K. R. Devabalaji, and K. Ravi, Optimal Placement and Sizing of DSTATCOM Using Harmony Search Algorithm, Elsevier B.V., 79 (2015). https://doi.org/10.1016/j.egypro.2015.11.563 
[15] A. K. Arya, A. Kumar, and S. Chanana, Assessment of Deployment of DGs and D-STATCOMs in Distribution Network using Gravitational Search Algorithm, Int. J. Recent Technol. Eng., 8 (2020) $119-127$. https://doi.org/10.35940/ijrte.d9009.018520

[16] A. H. Mashal ,R. H. Al-Rubayi and Mohammed Kdair Abd, Optimum Simultaneous Distributed Generation Insertion and Distribution Networks Reconfiguration for Losses Minimizaton Acknowledgment, M.Sc. thesis, Electrical power engineering., Univiversity of Technology., Baghdad., Iraq, 2020.

[17] R. Sirjani and A. Rezaee Jordehi, Optimal placement and sizing of distribution static compensator (D-STATCOM) in electric distribution networks: A review, Renew. Sustain. Energy Rev., 77 (2017) $688-694$. https://doi.org/10.1016/j.rser.2017.04.035

[18] S. Ganesh and R. Kanimozhi, Meta-heuristic technique for network reconfiguration in distribution system with photovoltaic and D-STATCOM, IET Gener. Transm. Distrib., 12 (2018) 4524-4535. https://doi.org/10.1049/ietgtd.2018.5629

[19] S. Rezaeian-Marjani, S. Galvani, V. Talavat, and M. Farhadi-Kangarlu, Optimal allocation of D-STATCOM in distribution networks including correlated renewable energy sources, Int. J. Electr. Power Energy Syst., 122 (2019) 106178 2020. https://doi.org/10.1016/j.ijepes.2020.106178

[20] A. Selim, S. Kamel, L. Nasrat, and F. Jurado, Voltage Stability Assessment of Radial Distribution Systems Including Optimal Allocation of Distributed Generators, Int. J. Interact. Multimed. Artif. Intell., 6 (2020) 32. https://doi.org/10.9781/ijimai.2020.02.004

[21] B. Singh and M. K. Yadav, GA for enhancement of system performance by DG incorporated with D-STATCOM in distribution power networks, J. Electr. Syst. Inf. Technol., 5 (2018) 388-426 . https://doi.org/10.1016/j.jesit.2018.02.005

[22] K. Rabyi and H. Mahmoudi, Energy storage of DFIG based wind farm using D-STATCOM, Int. J. Electr. Comput. Eng., 9 (2019)761. https://doi.org/10.11591/ijece.v9i2.pp761-770

[23] B. Bakhshideh Zad, J. Lobry, and F. Vallée, Coordinated control of on-load tap changer and D-STATCOM for voltage regulation of radial distribution systems with DG units, 2013 3rd Int. Conf. Electr. Power Energy Convers. Syst. EPECS 2013, no. November 2014 (2013). https://doi.org/10.1109/EPECS.2013.6712983

[24] T. Yuvaraj, K. Ravi, and K. R. Devabalaji, DSTATCOM allocation in distribution networks considering load variations using bat algorithm, Ain Shams Eng. J., 8 (2017) 391-403. https://doi.org/10.1016/j.asej.2015.08.006

[25] Hidayatullah, N.A., Paracha, Z.J. and Kalam, A., Impacts of distributed generation on smart grid, M.Sc. thesis, Electrical engineering., Victoria University., Malaysia. (2011).

[26] F. Zhang and C. S. Cheng, A modified Newton method for radial distribution system power flow analysis, IEEE Power Eng. Rev., 17 (1997) 68.

[27] X.She Yang, Engineering Optimization An Introduction with Metaheuristic Applications. John Wiley Sons, ISBN 978-0470-58246-6. (2010).

[28] A. Lasmari, S. Semaoui, C. Z. El-bayeh, and H. A. Hassan, Optimal energy management system for distribution systems using simultaneous integration of PV-based DG and DSTATCOM units, 66(2020) 1-14. https://doi.org/10.6001/energetika.v66i1.4294

[29] K. R. Devabalaji and K. Ravi, Optimal size and siting of multiple DG and DSTATCOM in radial distribution system using Bacterial Foraging Optimization Algorithm, Ain Shams Eng. J., 7 (2016) 959-971. https://doi.org/10.1016/j.asej.2015.07.002

[30] M.R. Nasser ,I. I. Ali and M. H. Alkhafaji, Power Management Strategies for a Microgrid, M.Sc. thesis, Electrical power engineering., Univiversity of Technology., Baghdad., Iraq, (2020).

[31] L. F. Grisales-Noreña, D. G. Montoya, and C. A. Ramos-Paja, Optimal sizing and location of distributed generators based on PBIL and PSO techniques, Energies, 11 (2018) 1-27. https://doi.org/10.3390/en11041018

[32] E. Ali, Geographic Information System ( GIS ): Definition , Development , Applications \& Components, no. March, (2020). 